\title{
Produção e composição do leite e escore corporal de cabras lactantes submetidas à suplementação mineral comercial e seletiva ${ }^{1}$
}

\author{
Pedro Malafaia ${ }^{2 *}$, Paula Barroso $\mathrm{Cruz}^{3}$ e Vinícius Pimentel Silva ${ }^{2}$
}

\begin{abstract}
Malafaia P., Cruz P.B. \& Silva V.P. 2014. [Milk production, composition and body condition score of lactating goats receiving two types of mineral mixtures.] Produção e composição do leite e escore corporal de cabras lactantes submetidas à suplementação mineral comercial e seletiva. Pesquisa Veterinária Brasileira 34(2):119-122. Departamento de Nutrição Animal e Pastagem, Instituto de Zootecnia, Universidade Federal Rural do Rio de Janeiro, Seropédica, RJ 23851-970, Brazil. E-mail: malafaia_ufrrj@yahoo.com.br

Comparison of milk production and composition, body condition score and the cost of commercial or selective mineral supplementation was made using two groups of 16 lactating goats during 164 days. No significant difference in milk production between treatments was found. There was no effect of the type of mineral supplement on the composition of milk fat, protein and lactose as well as on the somatic cell count (SCC). The average of daily intake of the commercial supplement was 1.76 times greater than the supplement containing only sodium chloride associated with copper sulfate. The use of the selective mineral mixture based on clinical-nutritional examination of the animals led to a reduction of about 7 times the amount spent by mineral supplementation of this goat herd.
\end{abstract}

INDEX TERMS: Goats, milk, mineral deficiencies, mineral supplementation.

RESUMO.- A comparação da produção e composição do leite, do escore corporal e dos custos com a suplementação mineral comercial e seletiva foi feita utilizando-se dois grupos de 16 cabras lactantes por 164 dias. Não houve diferenças significativas na produção de leite dos animais que ingeriram os dois tipos de suplementos minerais. Não houve efeito do tipo de suplementação mineral em relação a composição do leite em gordura, proteína e lactose bem como na contagem de células somáticas (CCS). 0 consumo médio diário do suplemento comercial foi 1,76 vezes maior do que o suplemento contendo apenas cloreto de sódio associado ao sulfato de cobre. A utilização da mistura mineral seletiva, formulada com base no exame clínico-nutricional dos animais, gerou uma redução de aproximadamente 7 vezes o custo com a suplementação mineral do rebanho caprino.

\footnotetext{
${ }^{1}$ Recebido em 26 de setembro de 2013.

Aceito para publicação em 14 de dezembro de 2013.

${ }^{2}$ Departamento de Nutrição Animal e Pastagens, Instituto de Zootecnia, Universidade Federal Rural do Rio de Janeiro (UFRRJ), Seropédica, RJ 23851-970, Brasil. *Corresponding author: malafaia_ufrrj@yahoo.com.br

${ }^{3}$ Zootecnista, Êxito Rural Consultoria em Pecuária, Rua Professora Chiquita Fernandes 990, Araçatuba, SP 16025-100, Brasil. E-mail: paulabarrosocruz@hotmail.com
}

TERMOS DE INDEXAÇÃO: Caprino, produção de leite, deficiências minerais, suplementação mineral.

\section{INTRODUÇÃO}

De uma forma geral as deficiências minerais, nos animais de produção, ocorrem ou estão associadas a determinadas áreas geográficas uma vez que, em função dos diversos tipos de solos que as formaram, é possível existir áreas deficientes, subdeficientes e não deficientes (Tokarnia et al. 2010).

No Brasil, em função da massiva propaganda feita pelas empresas que comercializam suplementos minerais para ruminantes, o fornecimento desses nutrientes é feito de forma indiscriminada e à revelia dos sólidos conhecimentos sobre os aspectos clinico-nutricional e patológico que existem sobre o assunto. Geralmente não há uma correlação com as necessidades dos animais e se ignora o fato que os alimentos podem prover, totalmente ou em grande parte, as exigências dos distintos macro e microminerais (Tokarnia \& Döbereiner 1973, Tokarnia et al. 2000, Malafaia et al. 2004a, 2004b, Peixoto et al. 2005).

A suplementação mineral deve sempre se basear em um exame clínico-nutricional, que verifica se há deficiência ou não de um ou mais elementos no rebanho; caso haja, deve- 
-se suplementar apenas com o(s) mineral(is) deficitário(s) (Tokarnia et al. 2000, 2010). Esta conduta denominada suplementação mineral seletiva (Peixoto et al. 2003), além de corrigir eventuais estados carenciais, permite uma economia significativa nos custos com a suplementação mineral, pois a mistura mineral seletiva é mais barata e menos consumida quando comparada com as misturas minerais comerciais (Malafaia et al. 2004a, 2004b, Carvalho et al. 2014).

Em relação à suplementação mineral dos caprinos, baseada no fornecimento dos elementos sabidamente deficitários nos rebanhos, existem poucas publicações no Brasil. Há o estudo de Malafaia et al., (2004b) com caprinos de corte em fase de crescimento. Porém, para animais em lactação, não há nenhuma publicação sobre o assunto. Assim, com base no que foi exposto, objetivou-se comparar a produção e a composição do leite, o escore corporal e os custos com a suplementação mineral de cabras lactantes submetidas à suplementação mineral comercial e seletiva.

\section{MATERIAL E MÉTODOS}

0 experimento foi conduzido no período de 25 set. 2006 até 8 mar. 2007, totalizando 164 dias, em um capril com mais de 150 cabras em lactação, localizado no município de Duas Barras, RJ $\left(22^{\circ} 08^{\prime} \mathrm{S}\right.$ e $\left.42^{\circ} 30^{\prime} \mathrm{O}\right)$ cuja altitude média é de $850 \mathrm{~m}$.

Foram utilizadas 32 fêmeas puras da raça Saanen, pesando entre 39 e $55 \mathrm{~kg}$, entre a segunda e quarta lactações, com cerca de 10 a 20 dias de paridas, ordenhadas duas vezes ao dia, identificadas e distribuídas em duas baias de $20 \mathrm{~m}^{2}$ cujo piso era de terra batida. Os animais foram alocados em dois grupos experimentais, sendo um suplementado com uma mistura mineral seletiva formulada após o exame clínico-nutricional do rebanho e o outro com uma mistura mineral comercial dita "completa" (MMC) rotineiramente utilizada entre os caprinocultores, cuja composição por kg era de $125 \mathrm{~g} \mathrm{Na}, 140 \mathrm{~g} \mathrm{Ca}, 70 \mathrm{~g} \mathrm{P}, 10 \mathrm{~g} \mathrm{~S}, 9 \mathrm{~g} \mathrm{Mg}, 1120 \mathrm{mg} \mathrm{Cu}, 66 \mathrm{mg} \mathrm{I}$, $46 \mathrm{mg}$ Co, 675mg Fe, 15mg Se, 2700mg Zn, 1750mg Mn e 6mg de Cr. A mistura mineral seletiva continha apenas $398 \mathrm{~g}$ de $\mathrm{Na} / \mathrm{kg}$ e $1250 \mathrm{mg}$ de $\mathrm{Cu} / \mathrm{kg}$. A adição de cobre se deveu à nossa observação de acentuada acromotriquia periocular em ruminantes que não recebem suplementos minerais nessa região serrana do Estado do Rio de Janeiro.

Todos os animais recebiam sempre o mesmo volumoso (silagem de milho) ofertado ad libitum às $8,10,14$ e 16 horas. Após ser colocado na área de alimentação, o volumoso era uniformemente misturado com um concentrado (formulado sem mistura mineral), contendo farelo de trigo $(300 \mathrm{~g} / \mathrm{kg})$, fubá $(450 \mathrm{~g} / \mathrm{kg})$ e farelo de soja $(250 \mathrm{~g} / \mathrm{kg}) .0$ concentrado era oferecido na base de $300 \mathrm{~g} /$ cab./dia para a manutenção e mais $300 \mathrm{~g} / \mathrm{kg}$ de leite produzido. A oferta de silagem sempre proporcionou sobras de 5-10\% da quantidade colocada nos cochos. Após um período de uma hora, as sobras eram descartadas. Para os dois lotes, os suplementos minerais eram regularmente colocados em cochos feitos com pneus velhos, amarrados com uma corda e pendurados no teto das baias; quando as sobras estavam em torno de 5-10\% um novo reabastecimento era feito.

As pesagens da produção de leite foram realizadas com intervalos aproximados de 3 semanas até o final do experimento e as avaliações do escore da condição corporal ( 0 até 5 , com escala de 0,5 unidades) foram feitas no início (25/09/06), no meio $(30 / 11 / 06)$ e ao final do estudo (08/03/07). Amostras de leite foram obtidas (cerca de $100 \mathrm{~g}$ em cada ordenha) em 26/09/06 e em 10/1/07 e congeladas até seu envio para o laboratório para a estimativa dos teores de proteína (métodos 991.20 e 991.23 da AOAC, 1998), gordura (técnica 433/IV do IAL, 2005), lactose (técnica 432/IV do IAL, 2005) e extrato seco total (método 925.23 da AOAC, 1998). Nessas datas, também foram coletadas amostras para a estimativa da contagem de células somáticas (CCS) que foram realizadas através de contador eletrônico de células.

Na avaliação do escore corporal, por se tratar de uma variável qualitativa efetuou-se análise não paramétrica por meio do teste de Krusckal Wallis (5\%) e, os postos médios comparados pelo teste de comparações múltiplas de Dunn a $5 \%$. Os postos médios foram descritos em tabela com valores médios absolutos. As variáveis composição e produção do leite atenderam as premissas de homocedasticidade das variâncias e distribuição normal, sendo portanto efetuada a ANOVA a 5\% e, quando detectada significância, as médias foram comparadas pelo teste de Tukey a 5\% de probabilidade. As análises foram efetuadas utilizando-se o pacote de análises estatísticas SAEG (2007).

\section{RESULTADOS E DISCUSSÃO}

Não houve diferenças significativas na produção de leite dos animais que ingeriram a mistura mineral seletiva ou a comercial (Quadro1). Entretanto, houve efeito significativo do período em lactação sobre a produção de leite, em todos os distintos momentos de pesagens e o pico da lactação se deu na terceira pesagem, por volta dos 3040 dias pós-parto (Quadro1). Se a pressuposição, muitas vezes com base teórica ou com apelo comercial, que as denominadas misturas minerais comerciais (MMC), formuladas com inúmeros elementos, resolvessem todos os problemas carenciais ou melhorassem o desempenho dos animais, esta hipótese deveria ter sido confirmada e não foi. Essa pressuposição é mais arraigada quando se trata de animais em lactação, que possuem sabidamente maiores exigências nutricionais. Estudos anteriores também rejeitaram as hipóteses de que a suplementação com as denominadas MMC produziriam resultados superiores frente às suplementações baseadas nos exames clínico-nutricional dos rebanhos, muitas vezes feitas apenas com um ou dois minerais adicionados ao cloreto de sódio (Peixoto et al. 2003, Malafaia et al. 2004a, 2004b, Carvalho et al. 2014). Como os alimentos utilizados nessa caprinocultura eram produzidos por intermédio de práticas agronômicas adequadas (correção e fertilização do solo com adubos

Quadro1. Produção de leite em cabras da raça Saanen suplementadas com diferentes misturas minerais ao longo do período de lactação

\begin{tabular}{lccc}
\hline Datas das pesagens & \multicolumn{2}{c}{ Peso do leite (kg/animal/dia) } \\
\cline { 2 - 4 } & $\begin{array}{c}\text { Mistura mineral } \\
\text { seletiva }\end{array}$ & $\begin{array}{c}\text { Mistura mineral } \\
\text { comercial }\end{array}$ & Média \\
\hline $25 / 09 / 2006$ & 2,90 & 2,75 & $2,82^{\mathrm{AB}}$ \\
$11 / 10 / 2006$ & 3,11 & 2,91 & $3,01^{\mathrm{AB}}$ \\
$07 / 11 / 2006$ & 3,18 & 2,92 & $3,05^{\mathrm{A}}$ \\
$28 / 11 / 2006$ & 3,03 & 2,90 & $2,96^{\mathrm{AB}}$ \\
$20 / 12 / 2006$ & 2,98 & 2,80 & $2,89^{\mathrm{AB}}$ \\
$10 / 01 / 2007$ & 2,88 & 2,65 & $2,77^{\mathrm{B}}$ \\
$02 / 02 / 2007$ & 2,52 & 2,40 & $2,46^{\mathrm{C}}$ \\
$22 / 02 / 2007$ & 2,31 & 2,11 & $2,21^{\mathrm{D}}$ \\
$08 / 03 / 2007$ & 1,80 & 1,71 & $1,75^{\mathrm{E}}$
\end{tabular}

$\overline{\mathrm{CV} \%}=13,7$. Médias, seguidas por letras diferentes na coluna, diferem entre si pelo teste SNK $(\mathrm{P}<0,05)$. 
orgânicos e minerais) e os animais ingeriam concentrado formulado com base nas exigências nutricionais da espécie caprina, essa dieta praticamente supria as necessidades dos demais minerais, à exceção do $\mathrm{Cu}$ cuja deficiência, ainda que moderada, foi diagnosticada no rebanho. Dai que a suplementação com cobre, adicionado ao $\mathrm{NaCl}$, supriu essa deficiência e propiciou resultados similares entre os dois esquemas de suplementação mineral.

Quanto aos componentes sólidos do leite, não houve efeito $(P>0,05)$ do tipo de suplementação mineral em relação a composição em gordura, proteína e lactose (Quadro 2). Contudo, diferenças no teor de extrato seco foram observadas, com valores médios superiores em favor ao grupo suplementado com a mistura mineral comercial no segundo momento de coleta (Quadro 2). Além disso, foram observadas diferenças nos valores médios do porcentual de gordura, proteína e lactose associados aos dois distintos períodos do ciclo lactacional (Quadro 2), justificado pela diferença da fase de produção de leite que afeta a composição do mesmo.

Quadro2. Composição do leite de cabras Saanen suplementadas com diferentes misturas minerais em dois períodos do ciclo lactacional

\begin{tabular}{|c|c|c|c|c|c|}
\hline $\begin{array}{l}\text { Composição } \mathrm{St} \\
\text { do leite }\end{array}$ & Suplementação & $26 / 09 / 2006$ & $10 / 01 / 2007$ & Média & CV (\%) \\
\hline \multirow[t]{3}{*}{ Gordura (\%) } & Seletiva & 3,26 & 3,34 & 3,30 & 6,42 \\
\hline & Comercial & 3,15 & 3,41 & 3,41 & \\
\hline & Média & $3,21^{\mathrm{B}}$ & $3,37^{\mathrm{A}}$ & - & \\
\hline \multirow[t]{3}{*}{ Proteína (\%) } & Seletiva & 3,03 & 3,10 & 3,07 & 3,1 \\
\hline & Comercial & 3,08 & 3,14 & 3,11 & \\
\hline & Média & $3,05^{\mathrm{B}}$ & $3,12^{\mathrm{A}}$ & - & \\
\hline \multirow[t]{3}{*}{ Lactose (\%) } & Seletiva & 4,31 & 4,38 & 4,35 & 2,95 \\
\hline & Comercial & 4,23 & 4,33 & 4,28 & \\
\hline & Média & $4,27^{\mathrm{B}}$ & $4,35^{\mathrm{A}}$ & - & \\
\hline \multirow[t]{3}{*}{ Extrato seco (\%) } & \%) Seletiva & $10,97^{\mathrm{Ab}}$ & $11,56^{\mathrm{Aa}}$ & - & 2,13 \\
\hline & Comercial & $11,07^{\mathrm{Ab}}$ & $11,29^{\mathrm{Ba}}$ & - & \\
\hline & Média & - & - & - & \\
\hline \multirow[t]{3}{*}{$\operatorname{CCS}\left(1 \times 10^{3}\right)$} & Seletiva & 441781,2 & 426731,2 & 434256,2 & 28,9 \\
\hline & Comercial & 413787,5 & 446506,2 & 430146,9 & \\
\hline & Média & 427784,4 & 436618,8 & & \\
\hline
\end{tabular}

Médias seguidas por letras diferentes maiúsculas na coluna e minúsculas nas linhas diferem entre si pelo teste Tukey $(\mathrm{P}<0,05)$.

Em relação à contagem de células somáticas (CCS) também não foram detectadas diferenças entre os dois esquemas de suplementação mineral (Quadro 2). De forma similar ao explicado anteriormente, quando um rebanho é alimentado com dieta feita com alimentos de qualidade, não é de se esperar que o fornecimento adicional de minerais possa implicar em alterações significativas na composição do leite. No que diz respeito a CCS, sabe-se que essa variável depende muito mais dos aspectos associados à higiene durante a ordenha do que dos aspectos nutricionais, como divulgam algumas indústrias de suplementos minerais e vitamínicos no Brasil.

Houve diferença na variação do escore da condição corporal (ECC) dentro do ciclo lactacional e as cabras foram gradativamente melhorando o ECC à medida que a lactação avançava. Nas últimas semanas de lactação, a ingestão de alimentos pelo animal atende as suas necessidades de
Quadro 3. Escore de condição corporal (ECC) de cabras Saanen suplementadas com diferentes misturas minerais em diferentes fases do período de lactação

\begin{tabular}{lcc}
\hline Data das avaliações & \multicolumn{2}{c}{ Escore da condição corporal (ECC) } \\
\cline { 2 - 3 } & $\begin{array}{c}\text { Mistura mineral } \\
\text { seletiva }\end{array}$ & $\begin{array}{c}\text { Mistura mineral } \\
\text { comercial }\end{array}$ \\
\hline $25 / 09 / 2006$ & $2,81^{\mathrm{Ba}}$ & $2,78^{\mathrm{Ca}}$ \\
$30 / 11 / 2006$ & $2,90^{\mathrm{Ba}}$ & $3,03^{\mathrm{BCa}}$ \\
$08 / 03 / 2007$ & $3,50^{\mathrm{Aa}}$ & $3,62^{\mathrm{Aa}}$
\end{tabular}

Médias seguidas por letras diferentes maiúsculas na coluna e minúsculas nas linhas diferem entre si pelo teste de comparações múltiplas de médias não paramétrico de Dunn $(\mathrm{P}<0,05)$.

Quadro 4. Consumo e despesas com os dois tipos de suplementação mineral para cabras lactantes da raça Saanen

\begin{tabular}{lcc}
\hline & \multicolumn{2}{c}{ Tipo de suplementação mineral } \\
\cline { 2 - 3 } & $\begin{array}{c}\text { Mistura mineral } \\
\text { seletiva }\end{array}$ & $\begin{array}{c}\text { Mistura mineral } \\
\text { comercial }\end{array}$ \\
\hline Consumo médio diário (g/animal) & 7,6 & 13,4 \\
Preço do suplemento (R\$/kg) & 0,55 & 2,23 \\
Despesas em 164 dias (R\$/16 animais) & 11,0 & 78,4
\end{tabular}

mantença lactação e, ainda, o balanço positivo resultante da ingestão de matéria seca permitiu ganhar peso. Contudo, quando se comparou os dois tipos de suplementação mineral, percebeu-se que não houve diferença no ECC entre eles (Quadro3).

0 consumo médio diário do suplemento comercial foi 1,76 vezes maior do que o suplemento contendo apenas cloreto de sódio associado ao sulfato de cobre (Quadro 4). Essa diferença deveu-se ao fato da mistura comercial possuir menos cloreto de sódio $(125 \mathrm{gNa} / \mathrm{kg}=312,5 \mathrm{gNaCl} /$ $\mathrm{kg}$ ) em sua composição e da maior quantidade de sal no suplemento feito com base no exame clínico-nutricional do rebanho $(398 \mathrm{gNa} / \mathrm{kg}=995 \mathrm{gNaCl} / \mathrm{kg})$. Outro aspecto é a redução do custo da suplementação mineral - desde que não implique em danos à saúde dos animais - que a suplementação seletiva propicia (Quadro 4). Neste estudo, foi possível reduzir cerca de 7 vezes o gasto com a suplementação de cabras em lactação; fato já verificado em outros estudos (Malafaia et al. 2004a,b).

\section{CONCLUSÕES}

A suplementação mineral seletiva, proposta com base no exame clínico-nutricional de cabras em lactação resultou no seguinte:

- Manteve a produção e a composição do leite e o escore corporal;

- Foi uma medida profilática eficiente e;

- Reduziu o custo com a suplementação mineral do rebanho.

\section{REFERÊNCIAS}

AOAC 1998. Official Methods of Analysis. $16^{\text {th }}$ ed. Association of Official Analytical Chemists, Arlington, USA, p.3-120.

Carvalho C.A.B., Peres A.A.C., Premazzi L.M., Malafaia P., Carvalho M.I.A.B., Paciullo D.S. \& Costa V.A.C. 2014. Performance of dairy heifers raised on Xaraés palissadgrass (Brachiaria brizantha cv. Xaraés) pasture sup- 
plemented with two types of mineral mixture. Pesq. Vet. Bras. 34(1): 46-50.

IAL 2005. Normas Analíticas do Instituto Adolfo Lutz. São Paulo, SP. 1018p.

Malafaia P., Peixoto P.V., Gonçalves J.C.S., Moreira A.L., Costa D.P.B. \& Correa W.S. 2004a. Ganho de peso e custos em bovinos de corte submetidos a dois tipos de suplementos minerais. Pesq. Vet. Bras. 24(3):160-64.

Malafaia P., Pimentel V.A., Freitas K.P., Coelho C.D., Brito M.F. \& Peixoto P.V. 2004b. Desempenho ponderal, aspectos econômicos, nutricionais e clínicos de caprinos submetidos a dois esquemas de suplementação mineral. Pesq. Vet. Bras. 21(1):15-22.

Peixoto P.V., Malafaia P., Miranda L.V., Canella C.F.C., Canella Filho C.F.C. \& Vilas Boas F.V. 2003. Eficiência reprodutiva de matrizes bovinas de corte submetidas a três diferentes tipos de suplementação mineral. Pesq. Vet. Bras. 23(3):125-30.

Peixoto P.V., Malafaia P., Barbosa J.D. \& Tokarnia C.H. 2005. Princípios de suplementação mineral em ruminantes. Pesq. Vet. Bras. 25(3):195-200.

SAEG 2005. Sistema de Análises Estatísticas e Genéticas: manual do usuário. Universidade Federal de Viçosa, Viçosa, MG., 150p.

Tokarnia C.H. \& Döbereiner J. 1973. Diseases caused by mineral deficiencies in cattle raised under range conditions in Brazil: a review. Pesq. Agropec. Bras. 8(Supl.):1-6.

Tokarnia C.H., Peixoto P.V., Barbosa J.D., Brito M.F. \& Döbereiner J. 2010. Deficiências Minerais em Animais de Produção. Editora Helianthus, Rio de Janeiro. 191p. 